\title{
Target information does not affect cue differentiation
}

\author{
WILLARD N. RUNQUIST \\ University of Alberta, Edmonton, Alberta T6G 2E9, Canada
}

\begin{abstract}
Subjects learned paired associates varying in cue structure similarity to perfect recall and then were tested for cue discrimination while recalling the targets. Similarity still affected cue discrimination, the results being virtually indistinguishable from those obtained when the discrimination test did not involve recall. In a second experiment, similarity among targets was shown not to influence cue discrimination. Implications for theories of interference reduction are discussed.
\end{abstract}

The results of a recent series of experiments from the University of Alberta laboratory have placed serious limitations on what may be called the cue discrimination hypothesis of interference reduction (e.g., Runquist, 1975; Runquist, Pullyblank, \& Whyte, in press; Runquist $\&$ Sekulich, 1979). The basic assumption of the theory is that interference resulting when cues for different target memories are similar is reduced or eliminated by acquiring distinctive codes for the various cues. In one form or another, the theory has been widely held for several years (Anderson \& Bower, 1973; Gibson, 1940; Underwood, 1969).

Among the problems faced by the theory is the fact that the results of tests designed to assess cue discrimination and associative recall separately do not covary in ways expected by the theory (Runquist et al., in press). These tests for cue discrimination are conducted as follows: Following associative learning of cues and targets, the subject is presented a series of tests with the cues alone. On each test, all of the cues in the set except one are presented, followed by a single "probe" cue. Either the probe is one of the cues that appeared in the test series or it is the missing cue. The subject is required to classify the probe as "repeat" or "missing." Errors, particularly when the probe was the missing cue, are assumed to result from confusing the probe with one of the previously presented items.

In one critical experiment (Runquist et al., in press), subjects learned paired associate lists with highly similar cues until all targets could easily be recalled. When the cue discrimination test was administered, however, there were still substantial effects of similarity. If the subjects had indeed learned to generate distinctive codes for the cues in order to master the associative

Requests for reprints should be sent to the author at Department of Psychology, University of Alberta, Edmonton, Alberta T6G 2E9, Canada. Don Whyte aided in the data collection. This work was supported by Grant A088 from the Natural Sciences and Engineering Research Council of Canada. learning task, they certainly did not use this information to alleviate interference on the recognition task.

The conclusion that cue discrimination does not accompany associative learning clearly depends upon the validity of the recognition task as a measure of that process. The two experiments reported here were designed to bear upon certain aspects of this question.

\section{EXPERIMENT 1}

It has been assumed that the coding of cues that occurs on the cue discrimination test is the same as that occurring at the time of attempted recall. In the Runquist et al. (in press) experiment, the recognition test did not include associative recall. All that the subject had to do was keep track of the cues. In the present experiment, subjects had to attempt recall to each cue in the series, including the probe. This procedure should make it more likely that the subject would code the cue for recall rather than devise new codes just to perform the recognition task.

\section{Method}

The experiment was an exact replication of Runquist et al. (in press), except for the recall requirement during the recognition test. Details of the experiment not reported herein are available in that paper.

The basic procedure was as follows. Each subject learned a six-pair paired associate list by alternating study and test presentations to a criterion of five consecutive perfect tests. Presentation rate was $2 \mathrm{sec}$ for both study and test. The lists consisted of consonant trigrams paired with nouns. There were four types of lists, varying in the pattern of letter commonality among the trigrams. Examples of the four types of cue sets are as follows: low similarity-XJB, ZMV, KDL, QFN, CPH, GTW; position constant-JBX, MBX, XDB, XFB, XBP, XBT; nonruleJBX, JMF, XDJ, BPX, TPF, TDM.

After reaching criterion, subjects were given the recognition test, which consisted of 12 consecutive test sequences. In each sequence, five of the six cues were presented, followed by the probe, which was either one of the five just presented or the missing one. The subjects tried to recall the correct noun to each of the five test cues. This was paced at $2 \mathrm{sec}$. When the probe appeared, the subject first classified the probe as repeat or miss- 
Table 1

Percent Correct Recognitions Before and After Associative Learning

\begin{tabular}{|c|c|c|c|c|c|c|c|c|c|}
\hline \multirow[t]{2}{*}{ Group } & \multicolumn{3}{|c|}{ Before* } & \multicolumn{3}{|c|}{$\begin{array}{c}\text { After } \\
\text { No Recall* }\end{array}$} & \multicolumn{3}{|c|}{$\begin{array}{l}\text { After } \\
\text { Recall } \\
\end{array}$} \\
\hline & $\mathrm{R}$ & $\mathbf{M}$ & $\mathrm{T}$ & $\mathbf{R}$ & $\mathbf{M}$ & $\mathrm{T}$ & $\mathbf{R}$ & M & $\mathrm{T}$ \\
\hline Low Similarit & 88 & 95 & 92 & 92 & 92 & 92 & 94 & 89 & 91 \\
\hline Position Constant & 80 & 78 & 79 & 94 & 84 & 89 & 92 & 86 & 89 \\
\hline Position Varied & 76 & 80 & 78 & 84 & 78 & 81 & 80 & 84 & 82 \\
\hline Nonrule & 77 & 67 & 72 & 85 & 77 & 81 & 86 & 88 & 87 \\
\hline
\end{tabular}

Note $-R=$ repeat,$M=$ missing, $T=$ total.

${ }^{*}$ Data from Runquist et al. (1982).

ing and then attempted to recall its target. No time limit was imposed. Each cue was omitted twice and was probed once as a repeat and once as a missing item.

The subjects were 64 introductory psychology students who participated as part of a course laboratory requirement. They were assigned to conditions as they appeared at the laboratory, according to a scheme that randomized the order of conditions within blocks containing each condition once.

\section{Results and Discussion}

Mean trials to criterion for the four groups were low similarity, 22.8, position constant, 34.6 , position varied, 39.8 , and nonrule, 28.4. The results were very similar to those obtained in other experiments using these lists, except for the nonrule group, which inexplicably learned more quickly than usual. Differences among the above means were significant $[F(3,60)=4.69$, $\mathrm{p}=.005]$.

The critical data are presented in Table 1 . Percent correct recognitions of the probe cue from both this experiment and the Runquist et al. (in press) experiment are included in the table. The latter data indicate performance on the recognition test without recall both before and after associative learning. Data from the present experiment appear in the final three columns.

Discrimination performance with recall is remarkably similar to that without. While the difference in performance between lists fell just short of significance $[F(3,60)=2.20, p=.09]$, it may be noted that $(1)$ the nonrule group performed better during acquisition than did its predecessor in the Runquist et al. (in press) study and probably consisted of better subjects, (2) power in this experiment was less because there were fewer subjects per condition (16 vs.20), (3) there was some ceiling effect in the low-similarity and position-constant conditions, and (4) when the data of the two experiments were combined, the interaction of recall/no recall with cue structure was not significant $(F<1.00)$.

The conclusion is that attempted recall of targets does not appreciably affect performance on the cue recognition test.

\section{EXPERIMENT 2}

A second assumption implicit in the cue discrimination test is that it is based on cue information alone. However, it is possible for the subject to perform the recognition task by recalling the target and then to make the recognition decision on the basis of whether that target had been recalled before. If this is the case, then parameters of the target information should have an effect on the cue discrimination test. Therefore, in this experiment, both cue and target similarity were varied.

\section{Method}

Subjects received 15 alternating study and test presentations on six pairs followed by the 12 recognition sequences. Procedural details were essentially the same as those in Experiment 1 , except that no recall was required during the discrimination test and all presentation orders were randomized.

There were four conditions combining high and low similarity of cues with high and low similarity of targets. The pairs consisted of consonant trigrams and two-syllable adjectives. The low-similarity and position-varied structures were used as cue sets. The targets were either relatively synonymous or relatively unrelated. Four different lists of each type were used.

The subjects were 80 undergraduates obtained and assigned to conditions as before.

\section{Results}

The means of the total correct recalls on the 15 test trials and the percent correct decisions on the recognition test for each of the four conditions are presented in Table 2. Similarity among either cues or targets clearly produced interference with recall during acquisition. The main effects of both cue similarity $[F(1,76)=$ 10.07] and target similarity $[F(1,76)=7.56]$ were significant. The interaction was just short of normally acceptable reliability levels $[F(1,76)=3.51, p=.07]$. Generally, target similarity had less effect when cue similarity was high than when it was low, and vice versa. The important thing, however, is that both structural similarity among cues and semantic similarity among targets affected recall.

The discrimination test results were also quite clear. Cue similarity produced decrements in recognition, but target similarity had no effect $[\mathrm{F}(1,76)=32.47$ for cues

Table 2

Mean Correct Recall and Recognition: Experiment 2

\begin{tabular}{|c|c|c|c|c|c|}
\hline \multicolumn{2}{|c|}{ Similarity } & \multirow[b]{2}{*}{ Recall } & \multicolumn{3}{|c|}{ Discrimination } \\
\hline Cue & Target & & $\mathbf{R}$ & $\mathbf{M}$ & $\mathrm{T}$ \\
\hline Low & Low & 50.3 & 90 & 89 & 90 \\
\hline Low & High & 33.4 & 93 & 88 & 91 \\
\hline High & Low & 31.8 & 85 & 72 & 78 \\
\hline High & High & 28.6 & 85 & 63 & 74 \\
\hline
\end{tabular}

Note $-R=$ repeat, $M=$ missing, $T=$ total. 
and .45 for targets]. In addition, correct classification of repeat probes exceeded that for missing probes $[F(1,76)=15.16]$, and this factor interacted with cue similarity $[F(1,76)=7.87]$. The effect of cue similarity was greater on missing probes than on repeat probes.

\section{GENERAL DISCUSSION}

In one sense, the results of the two experiments are encouraging. The activation of target information appears to have little effect on cue discrimination. Although subjects could perform the recognition test just using target words, they do not apparently do so. Neither encouraging the subject to recall targets nor manipulating the availability of correct targets changes the effects of similarity on cue discrimination.

On the other hand, the failure of associative learning to transfer to the recognition test remains a puzzle. If the subject learns enough about the cues to achieve perfect recall, why cannot this information be utilized to avoid interference on the recognition test? It is clearly possible that discriminative coding of cues does not occur at all. Under conditions of heavy interference, retrieval of misinformation is inevitable, but the learner may recognize errors for what they are, reject them, and, if sufficient time is available, still be able to recall the correct target. Cue coding is not directly affected by the target information as some have maintained (Ellis \& Shumate, 1973), but rather, retrieved target information may activate discriminative aspects of cues in order to verify the correctness of this information. If the process is under strategic control, target-determined codes may not be produced when a cue is presented for recognition and recall until after the recognition decision is made. This scenario would reconcile apparent cue-target interaction effects with the present data.

A second possibility is that the conception of cued recall as a staged process is incorrect. People do not just code the cue and then use that code for retrieval. Rather, the cue directly activates the memory of the entire cue-target episode. The failure of associative learning and the nature of the target to affect recognition performance results from the failure of the task demands of the recognition test to provide conditions necessary for that activation (Tulving \& Thomson, 1973). Discriminative coding may occur, but at the level of the entire episodic trace, not just the cue.

\section{REFERENCES}

Anderson, J. R., \& Bower, G. H. Human associative memory. New York: Wiley, 1973.

Ellis, H. C., \& Shumate, E. C. Encoding effects of response belongingness and stimulus meaningfulness on recognition memory of trigram stimuli. Journal of Experimental Psychology, 1973, 98, 70-78.

Gibson, E. J. A systematic application of the concepts of generalization and differentiation to verbal learning. Psychological Review, 1940, 47, 196-229.

RUNQUisT, W. N. Interference among memory traces. Memory \& Cognition, 1975, 3, 143-159.

Runquist, W. N., Pullyblank, J. C., \& Whyte, D. The differential coding of nominally similar cues and interference in recall. Journal of Experimental Psychology: Learning, Memory, and Cognition, in press.

Runquist, W. N., \& Sekulich, C. Transfer of stimulus differentiation and perceptual selection rules. Journal of Experimental Psychology: Human Learning and Memory, 1979, 5, 326-336.

Tulving, E., \& Thomson, D. M. Encoding specificity and retrieval processes in episodic memory. Psychological Review, 1973, 80, 352-373.

UNDERWOOD, B. J. Attributes of memory. Psychological Review, 1969, 76, 559-573.

(Received for publication June 7, 1982.) 